\title{
Social-ecological resilience through a biocultural lens: a participatory methodology to support global targets and local priorities
}

\author{
$\underline{\text { Michael Ungar }}^{1}, \underline{\text { Jennifer McRuer }}^{1}$, Xiaohui Liu $^{1}$, Linda Theron $^{2}$, Daniel Blais $^{1}{ }^{\text {and Matthew A. Schnurr }}{ }^{1}$
}

\begin{abstract}
More research is needed to properly represent social-ecological system (SES) interactions that support the integrity of biological and cultural, i.e., biocultural, relationships in places experiencing environmental, economic, and social change. In this paper we offer a novel methodology to address this need through the development of place-based indicators and engagement of young people as coresearchers in two communities that rely on resource extraction industries (specifically, oil and gas) in Canada and South Africa. Young people's SES experiences were explored through a suite of participatory qualitative methods, including Q methodology, visioning exercises, ESRI Survey 123, participatory mapping and photography, and spatial image capture via unmanned aerial vehicles, i.e., drones. These methods support a biocultural approach to SES research that seeks to better understand the significant SES relationships at stake in changing environmental, economic, and social context. Here we present our research process and conclude that a focus on place supports the feedback loop between existing SES frameworks and local experiences. We suggest that this methodology can be amended for diverse localities and unique populations to support the development of efficacious policies, SES management, and community efforts toward building resilience, sustainability, and well-being of both humans and natural environments.
\end{abstract}

Key Words: biocultural relationships; oil and gas industry; participatory methodology; place; resource extraction; social-ecological resilience; social-ecological systems; youth

\section{INTRODUCTION}

Although studies of the dynamics within and between social and ecological systems (SES) is well founded (Pretty 2011), improved efforts to understand the impacts of systemic change in unique places are needed to inform and support SES monitoring goals (Newman et al. 2017). Social-ecological systems refers to the interdependent dimensions of human societies (including cultural, political, economic, technological, and material aspects) and natural ecosystems (Folke et al. 2016). The relationships between these dimensions have been typified by three overlapping interactions: (1) humans' influence on ecosystems; (2) the ecosystem's influence on human activities; and (3) the reciprocal feedback between humans and ecosystems (Scholz and Binder 2003, Scholz 2011). Each interaction represents a lens through which to explore diverse ways of being in the world, leading to a transdisciplinary interest with multiple methodologies for monitoring SES dynamics and change.

Monitoring SES change using mixed methods research is increasingly salient in our current epoch of the Anthropocene, where humans now influence ecosystems in locally nuanced and complex ways (Bennett et al. 2016). Those living in communities reliant upon resource-based industries, such as oil and gas, agriculture, forestry, or fishing, are being particularly affected by our rapidly changing environment and attitudes toward resource management, including people's experience of local resource availability, global markets and fluctuating commodity prices, and institutional or community level governance structures (Berkes et al. 2009, Perry et al. 2011, Robson et al. 2016, Teitelbaum et al. 2019). These changes to SES are likely to be experienced differently depending on the unique relationships between people in resource-dependent places and the ability of SES to adapt to change (Anguelovski et al. 2016). These differences based on place have led to broad efforts to monitor SES interactions and their impact on local biocultural systems.
One challenge to monitoring SES interactions lies in reconciling standardization with contextualization. Standardized frameworks, such as the UN's Sustainable Development Goals (UN 2019), designed to monitor SES interactions, tend to project allencompassing broad scale targets that can fail to account for local interactions. A need therefore arises to contextualize monitoring efforts to reflect the unique and diverse experiences of people and the physical places in which they live. One approach to this contextualization has been the use of public participation in scientific research (PPSR; Shirk et al. 2012). As Haywood et al. (2016) found, when people with the experience of a particular place are engaged in rigorous PPSR (which is commonly referred to as citizen science), whether designing the research or collecting and analyzing place-specific data, their knowledge of their ecosystem and their interactions with it are enhanced. So too is their sense of connection to place and understanding of how anthropogenic activities impact ecosystems in positive and negative ways.

Although PPSR requires place-specific research and contextualization, the methodologies required to carry out such research are still in development. To address this need for innovation, we adapted methodology based on place-based understandings of SES to engage young people from two different communities (one in Canada, the other in South Africa) dependent on the oil and gas industry. Specifically, by supporting citizen scientists and focusing on place-specific SES interactions, we were able to identify the most relevant indicators of resilience, sustainability, and well-being to the two study communities that both rely heavily on resource-extractive industries. Given that there is a growing call for participatory approaches in SES research (Shirk et al. 2012, Vaidya and Mayer 2014, Mistry et al. 2016), we examined a selection of domains through a complementary suite of qualitative participatory methods to explore young people's accounts of SES interactions in each 
research site. This methodology has helped to inform ongoing SES monitoring frameworks based on relationships with place. Our goal here is to propose our methodology as a possible way of linking citizen science, place-based data, and interventions to address problems confronting SES. Although data analysis is continuing and will be reported in forthcoming publications, in this article we discuss the process of designing and implementing place-specific participatory research methods and their importance to SES monitoring frameworks.

\section{Contextualizing existing SES frameworks}

Existing SES frameworks tend to fall under umbrella themes of resilience, sustainability, and well-being, which represent the processes and resultant states of SES interactions (Lew et al. 2016, Marchese et al. 2018). One oft-cited challenge with the implementation of such SES frameworks is that they tend to offer macroscopic targets designed for global interventions despite their intentions to invest in localized processes (Folke et al. 2005, Mistry et al. 2016, Reddy 2016). For example, an increase in environmental sustainability efforts may lead to decreased economic well-being for a coal-mining community, or to a decrease in connection to traditional cultural practices of hunting and fishing for a rural Indigenous community. In both scenarios, an increase in sustainability practices may influence resilience through a loss of cultural connection or loss of access to employment. This oversight not only obscures opportunities to understand local processes tied to place (Caillon et al. 2017), but also thwarts global targets by potentially introducing bias, misinterpretation, and distortion (Liverman 2018). Conversely, when local processes are taken into consideration and alter existing global SES frameworks, they are often too specific to be universally adapted (Hicks et al. 2016). Compounding this need for mutual translation from global to local scales is the normative nature of the targeted themes of resilience, sustainability, and well-being. These themes do not imply universal understandings or desired states across all cultures, and thus require contextualization to ensure the relevance of monitoring approaches and frameworks (Marchese et al. 2018). This lack of resonance has the potential to misguide policy, planning, and management decisions at both local and global levels.

\section{Thematic conceptualization of resilience, sustainability, and well- being}

The themes of resilience, sustainability, and well-being have become important indicators of SES. Because our objective is to identify SES frameworks that provide opportunities to explore social and ecological interactions in resource-dependent communities in ways sensitive to place, and apply those frameworks to improve local place-based data collection practices, we chose to examine each theme in more detail.

Resilience has multiple definitions across a variety of fields, including engineering, ecology, development, economics, psychology, and health (Berkes and Ross 2013, Engle et al. 2014, Quinlan et al. 2016, Ungar 2018). In the SES literature, resilience broadly describes the ability of both people and environments to adapt over time to disturbances, disruptions, uncertainties, vulnerabilities, and risks, while remaining within critical thresholds that sustain a system's functioning (Walker et al. 2004, Folke et al. 2010). The concept of resilience, from an SES perspective, refers to goals of adaptive capacity, learning, and innovation (Quinlan et al. 2016). Resilience is concerned with adaptation to vulnerability, including fostering favorable relationships and states when the need arises (Redman 2014, Didkowsky 2016). It is important to note, however, that resilience is not always a desirable attribute of a system, as SES interactions considered resilient in one context may lead to undesirable outcomes depending on temporal, social, and spatial scales (Carpenter et al. 2001). For example, communities experiencing resource dependency, e.g., on oil and gas, fisheries, or forestry industries, may experience a lack of SES resilience due to environmental stress and economic vulnerability during "bust" periods, while institutions supporting associated market economies may experience resilience (Adger 2000).

An emphasis on "resilience of what, to what, and for whom" draws attention to (a) how desirable and undesirable states are conceptualized; (b) how desirable and undesirable states are experienced; and (c) the factors that affect what a desirable or undesirable state is. Such reflection leads us to question not only the role of resilience and adaptation in shaping SES change, but also what social and natural resources are deemed worthy of conservation (Walker and Salt 2006, Magis 2013, Lew et al. 2016), the impact of sustainable development strategies on different communities, and the well-being of those residing there. Roberts (2015) describes sustainable development as the process of responsible use of social and natural resources to support current and future generations. Breslow et al. (2016:251), meanwhile, describe well-being as "the state of being with others and the environment, which arises when human needs are met, when individuals and communities can act meaningfully to pursue their goals, and when individuals and communities enjoy a satisfactory quality of life."

Studies of well-being have suggested that the concept has been insufficiently understood in its relation to SES interactions (Smith 2013), and that place-based research approaches are needed to better understand how the two are interdependent (Hicks et al. 2016, McCarter et al. 2018). Although research on resilience and well-being at both individual and community levels has been extensive (e.g., Cutter et al. 2008), identifying links between all three concepts (resilience, sustainability, and well-being) in different localities could benefit from further research that includes greater participation from diverse populations, including young people.

Place-based SES contextualization using participatory processes A focus on place provides a means of targeting local realities and experiences because it represents the reciprocal interactions between humans and ecosystems through an entanglement of knowing and being, nature and culture, and human and nonhuman relations (Whatmore 2002). From a social perspective, place is "space which people have made meaningful" (Cresswell 2004:7) bounded by geographical and political cartography, as well as boundless as a result of dynamic influences of space and time, social values, meanings, practices, identities, histories, local and global processes, power relations, mobilities, and human and nonhuman enactments (Cloke and Jones 2001, Cresswell 2004, Ingold 2005, Massey 2005, Booth 2015). A commitment to placebased knowledge and perspectives brings a biocultural approach to understanding SES. Rather than being bound by the conceptual domains of SES frameworks, biocultural approaches 
refer to community-based processes whereby those most connected with place dictate the conceptual domains and associated indicators of significance to them (Reed et al. 2006). As Sterling et al. (2018) showed, biocultural approaches are always social-ecological in nature, but not all social-ecological approaches are biocultural; that is, not all embrace local, placebased, and culturally grounded foundations.

Participatory methods have the potential to elicit grounded understandings of SES interactions by directly engaging those most impacted by change (Newman et al. 2017, McCarter et al. 2018). For example, participatory methods such as transect walks, focus groups, and participatory mapping have been used to understand how Maasi herders interpret environmental change (Jandreau and Berkes 2016); cultural landscape mapping has been used to assess Aboriginal people's intangible connections to ecosystems in rainforests (Pert et al. 2015); and community asset mapping has assessed social and ecological assets across Peruvian Amazon communities (Wali et al. 2017). These examples demonstrate how participatory methods carried out with careful attention to place can produce uniquely situated understandings of SES change and their impacts on everyday lives. Newman et al. (2017), for example, have identified several advantages of paying attention to place when conducting citizen science that is intended to influence environmental policy, including increased knowledge mobilization that emphasizes the impact of interventions on outcomes. Without considering the significance of place, indicators that have little significance to local contexts may be overemphasized, while those with the most significance may be overlooked. Moreover, without a focus on place, it can be challenging to generate local community support, or sustained effort to meet collective goals (Wali et al. 2017).

In some cases, participatory processes may rely solely on firsthand accounts of biocultural relationships in order to discern SES interactions and monitoring needs (McCarter et al. 2018). For example, Vaidya (2016) elicited community input to determine sustainability criteria and indicators for assessing sustainability of the forest-based bioenergy industry in Michigan. In other cases, an existing SES framework has been used to guide participatory processes to ascertain how biocultural relationships relate to local contexts. For example, the Mauri Model Decision Making Framework (Morgan 2008) offers four consistent metrics that can be scored based on community-identified SES relationships. Other approaches offer specific sets of indicators that can be adapted to diverse settings. One such example is the resilience measurement tool, which includes 76 indicators intended to support household responses to disaster and climate-change (Committee on Sustainability Assessment 2018). Still other approaches may use SES frameworks to guide comparison of particular indicators, while leaving space for community-defined targets that reflect place-specific relationships (McCarter et al. 2018).

\section{THE RESILIENT YOUTH IN STRESSED ENVIRONMENTS (RYSE) STUDY}

Study communities

RYSE is a 5-year multiphase research project that is examining the resilience of young people aged 15-24 at biological, psychological, social, and ecological levels in communities dependent on oil and gas industries, specifically Drayton Valley, Alberta, Canada, and Secunda, Mpumalanga Province, South Africa. One phase of the project, the focus of this paper, specifically examines youths' SES experiences to determine the place-based human-environment interactions that are most significant to their lives.

Drayton Valley was established in 1953, approximately $133 \mathrm{~km}$ southwest of Edmonton, Alberta, the largest oil-producing province in Canada. Home to approximately 7000 people, it is situated on Treaty 6 Territory, traditional home of Plains Cree and Métis Indigenous peoples. Largely dependent on oil and gas extraction, agricultural and forestry sectors, Drayton Valley is surrounded by vast stretches of farmland, dotted by the rise and fall of pump jacks extracting oil. The North Saskatchewan River flows to the east of Drayton Valley, creating a setting for a provincial park. The town's Municipal Council has been working for several years to create a more sustainable economy in response to boom-and-bust cycles in the oil and gas sector. From 1996 to 2018, Drayton Valley experienced five boom and bust periods. Most of the workforce over the age of 15 was employed by oil and gas industries during this time period, with a slight decrease during bust years. Health care and social assistance, construction, and manufacturing are other predominant employment sectors (X. Liu, J. McRuer, M. Schnurr, D. Blais, L. Theron, and M. Ungar, unpublished manuscript). During this same period, there has been a decreasing trend in the area of water (e.g., lakes. rivers), wetland and barren land (e.g., unused open area), and forest area cover, and an increasing trend in the amount of land being converted to agriculture. Young people aged 15-19 years old compose $5.35 \%$ of the population; 20-24-year-olds make up 7.88\% (Statistics Canada 2017).

eMbalenhle is a small township proximate to the more developed town of Secunda, located approximately $150 \mathrm{~km}$ east of Johannesburg, South Africa. Secunda is part of the Govan Mbeki Municipality, located in the third poorest province of Mpumalanga (one of South Africa's poorer provinces). Vast coalfields surround the town which counts among its assets the largest underground coal-mining complex in the world (Govan Mbeki Municipality 2019). Secunda was established in the 1970s to support natural resource extraction and production. The human-made backdrop of this community includes hillsides of compacted gold mine dust, and factory smokestacks rising from a coal liquefaction plant, actively producing synthetic fuel, petroleum, paraffin, jet fuel, creosote, bitumen, diesel, and lubricants. In 2014, this plant was cited as the largest $\mathrm{CO}_{2}$ emitter in the world (Death 2014), while also noted as significant for continual job creation opportunities and community investment (Mondliwa and Roberts 2019). In 2011, Secunda was home to approximately 40,000 people, with approximately 250,000 more living in the wider Govan Mbeki municipal area, including $118,889\left(6050\right.$ persons $\left./ \mathrm{km}^{2}\right)$ in eMbalenhle (Statistics South Africa 2011). The unemployment rate in the wider municipality is $26 \%$, and $34.4 \%$ among youth aged 15 to 34 (Statistics South Africa 2011). In 2011, only $56 \%$ of households had access to inhome piped water, and this number has fallen slightly to $44.4 \%$ in 2016 (Statistics South Africa 2016). In November 2015, the provincial government identified Govan Mbeki municipality as severely drought affected, and disaster management was requested from the national government. Youth organizations in 
Secunda and governments have launched initiatives to increase the capacity of vulnerable young people and reduce poverty. Even so, the residents of eMbalenhle regularly engage in protests to draw attention to poor service delivery, structural violence, and corrupt governance (Mathebula 2017, 2018, 2019).

\section{Study participants}

For this qualitative phase of the study examining SES indicators, we engaged young people aged 18-24-years-old in both communities. Participant selection was based on youth having experience of place-based oil and gas industries, i.e., their parents being employed in the industry; migration on account of job opportunities (or lack thereof); interest/engagement in community development efforts to cope with the impact of the industry; science and environment-related studies oriented toward future employment in the industry.

In the Canadian study community, youth participants were identified through an application process disseminated through the Local Advisory Committee (LAC) and social media. Of the 18 young people who applied to participate, 10 were selected based on selection criteria, availability, and diversity of life experience. Participant numbers were capped at 10 on account of training capacities, e.g., drone workshop. All youth participants were between the ages of 18 and 24, with the exception of one youth who was 28 years old but expressed a high degree of interest and was recommended by an LAC member. Of the youth participants in this study, five identified as male, four as female, and one as nonbinary. Furthermore, four identified as Métis and six as Settler Canadians. Six were working in Drayton Valley, one worked in the surrounding area, i.e., Edmonton, and one was looking for work. All had completed high school, and four attended university/college or were applying for postsecondary degree programs in Alberta at large. All shared an interest in learning about the natural environment.

In the South African study community, young people were invited based on recommendations of a Youth Advisory Panel. Of the 12 eMbalenhle youth who participated in this research, six were Advisory Panel members. All youth participants were between the ages of 19 and 23, with five identifying as male and seven as female. All but one youth speak IsiZulu and Sepedi as their primary languages, and all are also proficient in English. All participants had completed high school, and were involved in classes to improve their marks, employed in entry-level positions, or were looking for employment.

\section{METHODOLOGY: THEORETICAL}

\section{Assessing crosscutting conceptual domains of local interest}

To discern conceptual domains that could be explored by the participants, members of the core research team began by transcribing and expanding Breslow et al.'s (2016) well-being constituents, domains, and subdomains into a tabular spreadsheet (see Table 1 for list of domains), then shared this list with participants to stimulate a broad understanding of the many aspects of SES. Based on review by the research team and participants, and based on young people's experiences in their community, 11 conceptual domains and 25 respective subdomains were selected as relevant to this study (indicated in Table 1 by an asterisk).
Table 1. List of human well-being categories, adapted from Breslow et al. (2016).

\begin{tabular}{|c|c|c|}
\hline Constituent & Conditions & $\begin{array}{l}\text { Selected } \\
\text { Domains }\end{array}$ \\
\hline Domain & Tangible Connections to Nature & * \\
\hline Subdomain & Resource Access \& Tenure & \\
\hline Subdomain & Access to nature & * \\
\hline Subdomain & Stewardship & * \\
\hline Domain & Intangible Connections to Nature & * \\
\hline Subdomain & Beauty and Inspiration & \\
\hline Subdomain & Sense of Place & * \\
\hline Subdomain & Spirituality & * \\
\hline Domain & Culture \& Identity & * \\
\hline Subdomain & Identity & * \\
\hline Subdomain & Cultural values and practices & * \\
\hline Subdomain & Heritage & * \\
\hline Domain & Social Relationships & * \\
\hline Subdomain & Family and Community & \\
\hline Subdomain & Civil Society & \\
\hline Subdomain & Social Diversity and Integrity & $*$ \\
\hline Constituent & Capabilities & \\
\hline Domain & Livelihood and Activities & * \\
\hline Subdomain & Subsistence & * \\
\hline Subdomain & Job Quality & \\
\hline Subdomain & Recreation and Tourism & * \\
\hline Subdomain & Time for Fulfilling Activities & \\
\hline Domain & Knowledge and Technology & * \\
\hline Subdomain & Education \& Information & * \\
\hline Subdomain & Research \& Technology & * \\
\hline Domain & Freedom \& Voice & * \\
\hline Subdomain & Political Participation & * \\
\hline Subdomain & Sovereignty & \\
\hline Domain & Governance \& Management & \\
\hline Subdomain & Resource Management & \\
\hline Subdomain & Public Services & \\
\hline Subdomain & General Governance & \\
\hline Constituent & Conditions & \\
\hline Domain & Health & * \\
\hline Subdomain & Food & * \\
\hline Subdomain & Physical Health & * \\
\hline Subdomain & Emotional and Mental Health & * \\
\hline Domain & Safety & * \\
\hline Subdomain & Disaster Preparedness & * \\
\hline Subdomain & Physical Safety & * \\
\hline Subdomain & Peace \& Security & * \\
\hline Domain & Economy & * \\
\hline Subdomain & Local \& informal economies & \\
\hline Subdomain & Material wealth and security & \\
\hline Subdomain & Employment \& Income & * \\
\hline Subdomain & Industry and Commerce & * \\
\hline Domain & Environment & * \\
\hline Subdomain & Infrastructure & $*$ \\
\hline Subdomain & Pollution \& Waste & * \\
\hline Subdomain & Environmental Quality & $*$ \\
\hline Subdomain & Resource Abundance \& Distribution & $*$ \\
\hline Constituent & Cross-Cutting & \\
\hline Domain & Equity \& Justice & \\
\hline Domain & Security & \\
\hline Domain & Resilience & * \\
\hline Domain & Sustainability & * \\
\hline
\end{tabular}




\section{METHODOLOGY: PRACTICAL CONSIDERATIONS}

Contextualizing framework domains using participatory methods We next designed a suite of participatory methods to discern the relevance of these preselected conceptual SES domains to young people's lives. Our intention was to elicit the domains most representative of the significant place relationships held among young people. Six participatory methods were selected for their potential to (i) facilitate place-based data collection, (ii) engage young people in domain contextualization, and (iii) support youth capacities as young researchers and stewards of their communities. Following recruitment, application, and consent processes, young people participated in an intensive 9-day workshop in Canada and 4-day workshop in South Africa (note: workshops were adapted to match the amount of time young people could commit to the study; the workshop in South Africa did not include training for young people in the operation of drones). The following are descriptions of each of the methods used with the youth to engage them as citizen scientists.

\section{$Q$ methodology}

In the context of our wider study, Q methodology was a means to better understand what domains are most relevant to youth's lives and was used to inform indicator development and prioritizing. We selected this method for its proven success in assessing values and perceptions of place-based SES interactions. Examples include eliciting public perception on energy discourses in relation to sustainability in Canada (Parkins et al. 2015); understanding Indigenous perspectives on climate change and community-based management approaches in Mexico and Colombia (Ambrosio-Albala and Mar Delgado-Serrano 2018); gauging support for, and socioeconomic impacts of natural resource management and extractive industries in Rwanda (Weldegiorgis and Ali 2016); and assessing cultural ecosystem values related to protected areas in Canada and the United Kingdom (Pike et al. 2015). The method has also been used to discern broad perceptions related to global targets and directions, for example, the relationships between conservation, economy, ecosystem priorities, and human well-being (Holmes et al. 2017).

In our study, Q methodology helped introduce SES concepts, elicit youth values, and discern congruencies and discrepancies among conceptual SES domains at both individual and group levels. It captured how young participants see themselves in connection with place, in positive, negative, and neutral ways, across time. Two value-neutral statements were designed to convey each of the 25 conceptual subdomains for a total set of 50 statements. Statements focused on former or current place experience, and future aspirations. For example, the domain/subdomain of "Conditions: Economy: Industry" was represented by the following two statements: "Oil and gas is the future of my community," and, "It is important to me that we diversify employment opportunities other than primary industries." Each statement was printed on $2 \times 2$-inch squares, and each participant received a complete set of statements. Additionally, participants were given a "Q sort board," or a pyramidal printout comprised of 50 boxes. The $\mathrm{Q}$ sort board was labeled on an agreement scale from left to right: left being disagreement (-4), right being agreement (+4). According to this scale, youth were asked to consider each statement in relation to their community, then place it on the Q sort board in terms of perceived importance.

\section{Visioning approach}

To further explore place relationships, an asset mapping exercise was carried out through a visual, interactive group method. The method was based on a visual approach by the Global Ecovillage Network (GEN) designed to teach the fundamental principles of sustainability and design (Gaia Education 2012). Similar methods have been used successfully in other studies, such as that by McCarter et al. (2018) who employed mental and drawn visioning exercises to assess natural resource use and biocultural integrity and well-being in the Soloman Islands, while photo-elicited visioning was used by O'Neill and Graham (2016) in an Australian coastal community to consider sea-level rise and climate change. On a wider scale, visioning methods are valued for their contribution to the codesign of transdisciplinary research related to transformational communities and sustainability (Tschakert et al. 2016). In our adaptation, core principles were illustrated as a mandala of visual cards to generate collaborative dialogue around local SES experiences. Each card was attributed to one of five categories: social, cultural, economic, ecological, and whole systems, and all were displayed in a circular fashion on the floor. Youth were invited to walk around the circle, consider their placespecific experiences that were related to each category, then record their perceptions of community assets, needs, and well-being on cards that were placed on the floor next to each category. Upon completion, notes were tabulated to determine the subdomains and categories of highest priority. Importantly, the mandala of cards remained in a communal space to afford time for independent visioning and collective discussion throughout the workshop.

\section{ESRI Survey123 and participatory photography}

We adopted the Environmental Research Institute's (ESRI) Citizen Science tool Survey123 for ArcGIS to understand youth priorities of the selected conceptual domains and subdomains. This tool is one example of a Global Information System (GIS) technology, an advancing area of study with the potential to engage people in new ways of social learning and sharing of spatial, place-based data. Examples of its use to publicly assess place-based change include education programs on environmental justice and disaster resilience in built environments (Meyer et al. 2018); participatory data collection on sociospatial contexts for place-based planning (Steinberg and Steinberg 2015); and citizenled scientific data collection related to visual pollution, i.e., perceptions of excessive, cultural intrusions of the built environment on natural landscapes, such as wind turbines, cell towers, billboards, and dilapidated buildings (Kelling 2018, Moorthy et al. 2018). This tool uses a digital tablet-interface with a GIS platform to tailor georeferenced field data collection based on tailored survey questions.

Specifically, in our study Survey123 facilitated rich capture of social-ecological place relationships. Using the survey, youth were prompted through a series of electronic smart-form fillable survey questions to answer predefined questions that subsequently prompted additional questions depending on their answers. The smart form platform supports many types of data input, such as rank ordering, closed-ended choices, open-ended descriptions, multiple choice, spatial location, and image capture. Smart form survey questions were based on the 25 selected conceptual subdomains, and aimed to target youths' place experiences related to land use impacts, drivers, and pressures; the role of industry, 
e.g., oil and gas, forestry, agriculture; ecosystem services and supports; and environmental risks. Moreover, the survey affords participatory photography, whereby youth were asked to visually capture and share changing place relationships related to social and ecological aspects of their community, as well as their future scenario predictions and descriptions of desirable and undesirable change.

Our intent with this method was to engage young people in geographic storytelling and participatory photography related to their first-hand accounts of community vulnerability, strengths, and change related to the impacts of the oil and gas industries, natural disasters, and climate change. Moreover, this method supports youths' skill development in applying interactive technology to researching community places.

\section{Participatory mapping}

Participatory mapping was next used to consider broader representations of interconnected community places and changing SES interactions. Both interactive and visual, this method engages youth perspectives and discussions of changing place relationships, and forecasts for future scenarios. In wider application, participatory mapping has significantly informed place-based, SES discourses. Examples can be seen in marine and coastal planning (Moore et al. 2017), and land use planning for change (Karimi and Brown 2017) in Australia; in a study of biocultural relationships among young people living in an ancestral territory of Colombia (McRuer and Zethelius 2017); as well as in research on landscape values and development preferences in the Faroe Islands (Plieninger et al. 2018). From a holistic perspective, Biggs et al. (2015) suggest participatory mapping as one tool that can be used to contextualize indicators of broad SES interactions and support sustainable development agendas across scales.

For our study, laminated spatial maps were created based on secondary data available from government databases. In the Canadian study community, three laminated maps of Drayton Valley town and surrounding areas depicted oil and gas infrastructure on land and below the surface; water catchment areas in connection with industrial impacts, i.e., oil and gas, forestry, agriculture; and green spaces, i.e., natural and undeveloped. In South Africa, four laminated maps depicted spatial images of historical land use and change specific to the eMbalenhle township across four times points (1987, 1996, 2008, 2018), while a fifth map focused on land use and infrastructure in eMbalenhle and the surrounding area. In both sites, young people worked in small groups to artfully depict their responses to question prompts. Questions were designed to facilitate conversations related to the conceptual domains through an emphasis on changes to place over time. For example, youth were asked to map the following: their favorite and least favorite environmental places, changes, pressures, drivers, and impacts; social innovation; ecosystem services and functions; natural and built environment vulnerability and disaster mitigation; ecological health; resource needs and use; and governance structures.

\section{Ecological monitoring}

During the workshops, young people were introduced to ecological monitoring techniques and the resulting data regarding the quality of air and water in their communities. Data collection processes were informed by scientific measures of physicochemistry for resource-dependent areas, e.g., oil and gas, agriculture, and forestry in Canada; and oil and gas in South Africa. Monitoring measures and field equipment were selected for educational potential but differed in each study community based on appropriateness of use, availability, affordability, reliability, and safety. For example, water quality in the Canadian community was monitored using the YSI Multiparameter with Quatro Cable to measure $\mathrm{pH}$, dissolved oxygen, conductivity, total hardness, and temperature. Additionally, a YSI 9500 photometer was used with the following reagents: ammonia, chloride, dissolved $\mathrm{O}_{2}, \mathrm{pH}$, nitrite, sulphate, salinity, phosphorus, and temperature. In South Africa, the Somerset Educational (Pty) Limited Microlife Water Quality Testing Kit was introduced as a means to monitor temperature, $\mathrm{pH}$, coliform bacteria, dissolved $\mathrm{O}_{2}$ and biodissolved $\mathrm{O}_{2}$, hardness, nitrites, nitrates, and chlorine as well as turbidity. In both sites, independent data collection was facilitated using Lamotte Insta-Test Natural Water 5-Way Test Strips to capture nitrate, nitrite, $\mathrm{pH}$, alkalinity, and total hardness. To assess the biological health of waterways, monitoring benthic macroinvertebrates, e.g., those visible to the naked eye, was also introduced in reference to standardized stream monitoring protocols.

In both the Canadian and South African sites, air quality was sampled using PurpleAir monitoring sensors. Youth participated in the installation of these sensors in community schools to monitor daily air quality, i.e., particulates of $2.5 \mathrm{ppm}$, over the duration of the study (data collection is ongoing). Additionally, in the Canadian study community, independent data collection was supported through Airbeam Air Monitor kits to detect daily changes in air quality over the period of study, i.e., particulate, humidity, and temperature. Although the air quality equipment that was used included only basic air quality measures, they were useful for both educational and engagement purposes, especially given their open-source data sharing platforms.

Monitoring water and air quality in this study was an experiential learning opportunity to investigate community places identified by youth for their particular significance during participatory mapping. The collected data were used to spark reflection on these vital ecological resources, their significance to well-being, and the factors that affect their health and the health of the community at large. In the wider literature, monitoring biotic and abiotic relations is a long-standing means of understanding place-based change. Most recently, significant efforts are underway to build public capacity and mobilize collective ecological data collection through citizen science programs locally and internationally (Chandler et al. 2017). For example, in mining-dependent communities, researchers have engaged the public in capturing and deciphering socio-political, ecological, and economic conditions, alongside personal values to understand SES interactions (Hufford and Taylor 2013). Monitoring of this nature has the advantage of building community investment in the future of community places.

\section{Unmanned aerial vehicles ( $U A V S$ )}

Youth participants in the Canadian community also received certified training in the use of unmanned aerial vehicles (UAVs), or drones, to capture spatial images of their communities. This course was a means to further engage young people in thinking 
about their place relationships from a novel vantage point, while also providing them with new skills to build their capacity as young professionals. Drones can be an important means of studying SES relationships and change (Tabor and Hewson 2018). For instance, they have been used to strengthen the traditional mapping of Indigenous people's territorial land claims in Indonesia (Radjawali et al. 2017), as well as monitor change in Indigenous communities in the face of developmental pressures and growing environmental degradation in Peru, Guyana, and Panama (Paneque-Gálvez et al. 2017). On a wider scale, Tabor and Hewson (2018) suggest that the growing applicability of remote sensing (including UAV) research to assess place-based relationships can ultimately strengthen resilience, sustainability, and well-being agendas. For this study, Canadian participants used the drones to visually document land use patterns in unpopulated areas of their wider community, then used the images in knowledge sharing activities to highlight changes to the local landscape.

As a whole, these participatory methods afforded data collection that illuminated a place-based narrative of youth experiences and perceptions of SES change. Q methodology, visioning, and ESRI Survey123 explore perceived connections with place. Participatory photography affords depictions of place significance, while drone image capture in Canada and participatory mapping in both study communities offered "bird's eye view" assessments of place. Cross-analysis between methods has helped us to develop a clearer picture of place significance, change, and biocultural relationships most relevant to young people themselves.

\section{DISCUSSION}

Supporting harmonious biocultural SES interactions requires comprehensive understandings of system dynamics and local interactions. Such understandings often aspire toward resilience, sustainability, and well-being - three themes driving efforts to improve SES. Common, overarching goals have most recently been re-envisioned, on a global level, through the UN SDGs, a guiding framework designed to mobilize united efforts toward healthy SES. In principle, this broad framework is ostensibly committed to enabling local participation in realizing common goals. However, similar to earlier global SES monitoring efforts (such as the Millennium Development Goals), care must be taken to consider the relevance of local values and experiences to ensure adaptation and adoption of these goals by community members. Moreover, research that uses SES frameworks to monitor overarching goals must consider how the frameworks lend themselves to local involvement and participation. This includes place-based considerations which, as the methodology described in this paper shows, can be well understood through the use of multiple approaches to PPSR.

Similar to Haywood (2014), Shirk et al. (2012), and others, we see the need for the inclusion of a sense of place in the methods employed to understand SES and people's interactions with multiple systems. We need more attention given to how place affects people's experience of both nature and the science that describes people's interactions with ecosystems. Our methods, however, provide practical approaches to accomplish what previous proponents of PPSR have encouraged, namely engaging citizen scientists in reflection on the meaning of local ecosystems using criteria that make these methods both rigorous and reproducible. The successful implementation of these approaches for contextualized data collection and engagement of young people in the RYSE project suggests that there is a need for both top-down and bottom-up approaches to SES assessment. In this paper, we presented an approach that aims to synthesize existing frameworks from international, national, and regional perspectives, with the accounts of those living in unique places of SES change in order to deepen our understanding of biocultural contextualization.

We are aware that our approach has both benefits and drawbacks. One challenge we encountered was in selecting appropriate SES domains given the vast number of available resources that may have been equally suitable to investigate SES interactions (see, for example, Binder et al. 2013). We attempted to select the most relevant frameworks to our study communities based on place and methodological intention, though another research team working with different resource-dependent communities will likely want to reconsider our list of domain indicators.

Despite this problem of narrowing our focus to a manageable number of foci, the participatory methods we used served as a means to invite multiple accounts of experiencing place and to contextualize existing SES frameworks. Our particular interest was to encourage the inclusion of the voices of young people in SES policy planning and management processes as they are too often overlooked. Although we strive to achieve what Shirk et al. (2012) describe as cocreation and collegial contributions, where participants take a great deal of ownership of the research, in actuality we were only able to initiate a collaborative project at best, given the constraints of having to design the research months before its implementation in order to secure funding. Although we can look closely at place and engage citizen scientists in that process, we must remain self-conscious of our inability as scientists to include young people in the selection and design of the methodologies we employ. We see fuller participation as a future aspiration. Nevertheless, we recognize that youth input is needed to enact solutions to today's SES concerns, and that their voices will govern ongoing processes into the future. By using participatory methods to encourage young people to participate in place-based reflection, rich accounts emerged related to conceptual domains of particular significance to their lives. These domains offer a critical launching pad toward ongoing monitoring of local SES change. Moreover, they have the potential to inform existing development targets based on everyday resonance and applicability in communities experiencing the impacts of resource extraction industries such as oil and gas.

Ongoing monitoring of SES change may involve engaging other community cohorts in participatory methods to inform synergistic and antagonist perspectives, innovative ideas, and goals. This includes calling on all community voices to ensure representation and inclusion toward current and future planning. It may also involve youth becoming cofacilitators of such processes to further support their professional and civil capacities (Lachance et al. 2019). Developing or assigning associated indicators to monitor the conceptual domains of highest significance (within or across cohorts) is also a critical step. From a capacity-building point of view, indicator development and 
pursuant monitoring of progress and outcomes ought to continue in a participatory fashion to further engage community members in shaping their place relationships in desirable ways (McGinnis and Ostrom 2014). Importantly, a critical consideration involves planning for indicator-based action to support collective SES goals and desirable change. Each of these suggestions has the potential to contribute to an ongoing coproduction of knowledge related to SES dynamics and change, thereby collapsing the gap between overarching SES goals and local realities.

\section{CONCLUSION}

In this research, we have considered how existing SES frameworks can be synthesized based on place-based relevance, such that common domains can be explored, contextualized, and prioritized by those most impacted by SES interactions. Employing participatory methods with young people, and empowering them as citizen scientists, is a worthwhile approach to engage youth in thinking about their biocultural relationships with place, and the conceptual domains most significant to their lives. Ongoing research can further this process by developing indicators specific to prioritized domains in order to monitor SES change and dynamics on both local and global scales.

\section{AUTHOR CONTRIBUTIONS}

Michael Ungar is the principal applicant for the RYSE project and developed the overarching six-phase concepts of the study, supervised research activities, and contributed to the writing of the final manuscript. Jennifer McRuer led the conception of the presented theoretical and qualitative methodological designs, was the primary field researcher and facilitator, performed qualitative data collection and formal analysis, and wrote the manuscript. Xiaohui Liu led the quantitative methodological design, was the secondary field researcher and facilitator, and performed secondary data collection and analysis. Daniel Blais took the lead for the redrafting of the paper and final editing. Linda Theron contributed to the conceptualization of the RYSE study, refinement of ecological methods for South Africa, and manuscript revision. Matthew A. Schnurr directly supervised research activities, contributed to theoretical conceptualization and methodological design, mentored data collection and data analysis phase, and reviewed multiple paper drafts.

Responses to this article can be read online at: http://www.ecologyandsociety.org/issues/responses. php/11621

\section{Acknowledgments:}

We are grateful for the support from our research team members working with the Resilient Youth in Stressed Environments (RYSE) Project. We also acknowledge the financial support of the Canadian Institutes of Health Research (CIHR; Grant number: IP2150708). Finally, we would like to sincerely thank the youth participants and local advisory members of Drayton Valley and eMbalenhle who gave their time in support of this research.
Data Availability Statement:

Datalcode sharing not applicable - no new datalcode generated

\section{LITERATURE CITED}

Adger, W. N. 2000. Social and ecological resilience: are they related? Progress in Human Geography 24(3):347-364. https://doi. org/10.1191/030913200701540465

Ambrosio-Albala, P., and M. Mar Delgado-Serrano. 2018. Understanding climate change perception in community-based management contexts: perspectives of two Indigenous communities. Weather, Climate, and Society 10(3):471-485. https://doi.org/10.1175/WCAS-D-17-0049.1

Anguelovski, I., L. Shi, E. Chu, D. Gallagher, K. Goh, Z. Lamb, K. Reeve, and H. Teicher. 2016. Equity impacts of urban land use planning for climate adaptation: critical perspectives from the Global North and South. Journal of Planning Education and Research 36(3):333-348. https://doi.org/10.1177\%2F0739456X16645166

Bennett, N. J., J. Blythe, S. Tyler, and N. C. Ban. 2016. Communities and change in the Anthropocene: understanding social-ecological vulnerability and planning adaptations to multiple interacting exposures. Regional Environmental Change 16(4):907-926. https://doi.org/10.1007/s10113-015-0839-5

Berkes, F., J. Colding, and C. Folke, editors. 2009. Navigating social-ecological systems: building resilience for complexity and change. Cambridge University Press, Cambridge, UK. https://doi. org/10.1017/cbo9780511541957

Berkes, F., and H. Ross. 2013. Community resilience: toward an integrated approach. Society and Natural Resources 26(1):5-20. https://doi.org/10.1080/08941920.2012.736605

Biggs, E. M., E. Bruce, B. Boruff, J. M. Duncan, J. Horsley, N. Pauli, K. McNeill, A. Neef, F. Van Ogtrop, J. Curnow, B. Haworth, S. Duce, and Y. Imanari. 2015. Sustainable development and the water-energy-food nexus: a perspective on livelihoods. Environmental Science \& Policy 54:389-397. https://doi. org/10.1016/j.envsci.2015.08.002

Binder, C. R., J. Hinkel, P. W. G. Bots, and C. Pahl-Wostl. 2013. Comparison of frameworks for analyzing social-ecological systems. Ecology and Society 18(4):26. http://dx.doi.org/10.5751/ ES-05551-180426

Booth, K. I. 2015. What a difference place makes: place gestalt and some methodological thoughts. Qualitative Inquiry 21 (1):20-27. https://doi.org/10.1177/1077800414542689

Breslow, S. J., B. Sojka, R. Barnea, X. Basurto, C. Carothers, S. Charnley, S. Coulthard, N. Dolšak, J. Donatuto, C. GarcíaQuijano, C. C. Hicks, A. Levine, M. B. Mascia, K. Norman, M. Poe, T. Satterfield, K. St. Martin, and P. S. Levin. 2016. Conceptualizing and operationalizing human wellbeing for ecosystem assessment and management. Environmental Science \& Policy 66:250-259. https://doi.org/10.1016/j.envsci.2016.06.023

Caillon, S., G. Cullman, B. Verschuuren, and E. J. Sterling. 2017. Moving beyond the human-nature dichotomy through biocultural approaches: including ecological well-being in 
resilience indicators. Ecology and Society 22(4):27. https://doi. org/10.5751/ES-09746-220427

Carpenter, S., B. Walker, J. M. Anderies, and N. Abel. 2001. From metaphor to measurement: resilience of what to what? Ecosystems 4(8):765-781. https://doi.org/10.1007/s10021-001-0045-9

Chandler, M., L. See, K. Copas, A. M. Z. Bonde, B. C. López, F. Danielsen, J. F. Legind, S. Masinde, A. J. Miller-Rushing, G. Newman, A. Rosemartin, and E. Turak. 2017. Contribution of citizen science towards international biodiversity monitoring. Biological Conservation 213:280-294. https://doi.org/10.1016/j. biocon.2016.09.004

Cloke, P., and O. Jones. 2001. Dwelling, place, and landscape: an orchard in Somerset. Environment and Planning A: Economy and Space 33(4):649-666. https://doi.org/10.1068\%2Fa3383

Committee on Sustainability Assessment. 2018. Simpler resilience measurement: tools to diagnose and improve how households fare in difficult circumstances from conflict to climate change. The Committee of Sustainability Assessment, Philadelphia, Pennsylvania, USA. [online] URL: https://thecosa.org/wpcontent/uploads/2018/04/COSA-FORD-Simpler-Resilience-MeasurementFull-20180413.pdf

Cresswell, T. 2004. Place: a short introduction. Blackwell, Oxford, UK.

Cutter, S. L., L. Barnes, M. Berry, C. Burton, E. Evans, E. Tate, and J. Webb. 2008. A place-based model for understanding community resilience to natural disasters. Global Environmental Change 18(4):598-606. https://doi.org/10.1016/j.gloenvcha.2008.07.013

Death, C. 2014. The green economy in South Africa: global discourses and local politics. Politikon 41(1):1-22. https://doi. org/10.1080/02589346.2014.885668

Didkowsky, N. K. 2016. A substantive theory of youth resilience in rural Nova Scotia. Dissertation. Dalhousie University, Halifax, Nova Scotia, Canada. [online] URL: https://dalspace.library.dal. ca/bitstream/handle/10222/71289/Didkowsky-Nora-PhD-INTEMarch-2016.pdf? sequence $=3 \&$ is Allowed $=\mathrm{y}$

Engle, N. L., A. de Bremond, E. L. Malone, and R. H. Moss. 2014. Towards a resilience indicator framework for making climate-change adaptation decisions. Mitigation and Adaptation Strategies for Global Change 19(8):1295-1312. https://doi. org/10.1007/s11027-013-9475-X

Folke, C., R. Biggs, A. V. Norström, B. Reyers, and J. Rockström. 2016. Social-ecological resilience and biosphere-based sustainability science. Ecology and Society 21(3):41. http://doi.org/10.5751/ ES-08748-210341

Folke, C., S. R. Carpenter, B. Walker, M. Scheffer, T. Chapin, and J. Rockström. 2010. Resilience thinking: integrating resilience, adaptability and transformability. Ecology and Society 15(4):20. http://doi.org/10.5751/ES-03610-150420

Folke, C., T. Hahn, P. Olsson, and J. Norberg. 2005. Adaptive governance of social-ecological systems. Annual Review of Environment and Resources 30:441-473. https://doi.org/10.1146/ annurev.energy.30.050504.144511
Gaia Education. 2012. Ecovillage design education: a four-week comprehensive course in the fundamentals of sustainability design. Version 5. Global Ecovillage Educators for a Sustainable Earth, Edinburgh, UK. [online]. URL: https://gaiaeducation.org/wpcontent/uploads/2017/02/EDE-Curriculum-English.pdf

Govan Mbeki Municipality. 2019. Integrated development planning (IDP) and budget process plan and time schedule 2018/2019. Govan Mbeki Municipality, South Africa. [online] URL: http://www.govanmbeki.gov.za/wp-content/reports/ idp budget process plan 201819.pdf

Haywood, B. K. 2014. A "sense of place" in public participation in scientific research. Science Education 98(1):64-83.

Haywood, B. K., J. K. Parrish, and J. Dolliver. 2016. Place-based and data-rich citizen science as a precursor for conservation action. Conservation Biology 30(3):476-486.

Hicks, C. C., A. Levine, A. Agrawal, X. Basurto, S. J. Breslow, C. Carothers, S. Charnley, S. Coulthard, N. Dolsak, J. Donatuto, C. Garcia-Quijano, M. B. Mascia, K. Norman, M. R. Poe, T. Satterfield, K. St. Martin, and P. S. Levin. 2016. Engage key social concepts for sustainability. Science 352(6281): 38-40. https://doi. org/10.1126/science.aad4977

Holmes, G., C. Sandbrook, and J. A. Fisher. 2017. Understanding conservationists' perspectives on the new-conservation debate. Conservation Biology 31(2):353-363. https://doi.org/10.1111/ cobi.12811

Hufford, M., and B. Taylor. 2013. Edgework and boundary crossings: assessing foundations for public ecology in the Appalachian region. Pages 99-110 in J. R. Craynon, editor. Environmental considerations in energy production. Society for Mining, Metallurgy, and Exploration, lnc., Englewood, Colorado, USA.

Ingold, T. 2005. Epilogue: towards a politics of dwelling. Conservation and Society 3(2):501-508.

Jandreau, C., and F. Berkes. 2016. Continuity and change within the social-ecological and political landscape of the Maasai Mara, Kenya. Pastoralism 6:1. https://doi.org/10.1186/s13570-016-0048ע

Karimi, A., and G. Brown. 2017. Assessing multiple approaches for modelling land-use conflict potential from participatory mapping data. Land Use Policy 67:253-267. https://doi. org/10.1016/j.landusepol.2017.06.004

Kelling, S. 2018. Technology developments for biodiversity monitoring and conservation. Biodiversity Information Science and Standards 2(e25833). https://doi.org/10.3897/biss.2.25833

Lachance, L., C. Watson, D. Blais, M. Ungar, G. Healey, M. Salaffie, P. Sundar, L. Kelly, and M. Legace. 2019. Strengthening child and youth programs: a look at inter-organizational mentoring strategies. Evaluation and Program Planning 76:101679. https://doi.org/10.1016/j.evalprogplan.2019.101679

Lew, A. A., P. T. Ng, C. C. Ni, and T. C. Wu. 2016. Community sustainability and resilience: similarities, differences and indicators. Tourism Geographies 18(1):18-27. https://doi. org/10.1080/14616688.2015.1122664 
Liverman, D. M. 2018. Geographic perspectives on development goals: constructive engagements and critical perspectives on the MDGs and the SDGs. Dialogues in Human Geography 8 (2):168-185. https://doi.org/10.1177/2043820618780787

Magis, K. 2013. Community resilience: an indicator of social sustainability. Society \& Natural Resources 23:401-416. https:// doi.org/10.1080/08941920903305674

Marchese, D., E. Reynolds, M. E. Bates, H. Morgan, S. S. Clark, and I. Linkov. 2018. Resilience and sustainability: similarities and differences in environmental management applications. Science of The Total Environment 613-614:1275-1283. https://doi. org/10.1016/j.scitotenv.2017.09.086

Massey, D. 2005. For space. SAGE, London, UK.

Mathebula, S. 2017. Calm returns to eMbalenhle after violent protests yesterday. The Ridge Times, 16 October. [online] URL: https://ridgetimes.co.za/100043/breaking-news-embalenhle-protesterstorch-municipal-building-trucks/

Mathebula, S. 2018. Post office goes up in flames during eMbalenhle service delivery protest. The Ridge Times, 27 June. [online] URL: https://ridgetimes.co.za/118346/emba-servicedelivery-protest-turn-violent/

Mathebula, S. 2019. Investigation will look at maladministration, fraud and nepotism. The Ridge Times, 29 November. [online] URL: https://ridgetimes.co.za/151467/investigation-will-lookmaladministration-fraud-nepotism/

McCarter, J., E. J. Sterling, S. D. Jupiter, G. D. Cullman, S. Albert, M. Basi, E. Betley, D. Boseto, E. S. Bulehite, R. Harron, P. S. Holland, N. Horning, A. Hughes, N. Jino, C. Malone, S. Mauli, B. Pae, R. Papae, F. Rence, O. Revo, E. Taqala, M. Taqu, H. Woltz, and C. E. Filardi. 2018. Biocultural approaches to developing well-being indicators in Solomon Islands. Ecology and Society 23 (1):32. https://doi.org/10.5751/ES-09867-230132

McGinnis, M. D., and E. Ostrom. 2014. Social-ecological system framework: initial changes and continuing challenges. Ecology and Society 19(2):30. http://dx.doi.org/10.5751/ES-06387-190230

McRuer, J., and M. Zethelius. 2017. The difference biocultural "place" makes to community efforts towards sustainable development: youth participatory action research in a marine protected area of Colombia. International Review of Education 63(6):847-870. http://dx.doi.org/10.1007/s11159-017-9690-x

Meyer, M. A., M. Hendricks, G. D. Newman, J. Horney, P. Berke, J. Masterson, G. Sansom, T. Cousins, S. Van Zandt, and J. Cooper. 2018. Participatory action research: tools for disaster resilience education. International Journal of Disaster Resilience in the Built Environment 9(4-5):402-419.

Mistry, J., A. Berardi, C. Tschirhart, E. Bignante, L. Haynes, R. Benjamin, G. Albert, R. Xavier, B. Robertson, O. Davis, D. Jafferally, and G. De Ville. 2016. Community owned solutions: identifying local best practices for social-ecological sustainability. Ecology and Society 21(2):42. http://dx.doi.org/10.5751/ ES-08496-210242

Mondliwa, P., and S. Roberts. 2019. From a developmental to a regulatory state? Sasol and the conundrum of continued state support. International Review of Applied Economics 33(1):11-29. https://doi.org/10.1080/02692171.2019.1523845
Moore, S. A., G. Brown, H. Kobryn, and J. Strickland-Munro. 2017. Identifying conflict potential in a coastal and marine environment using participatory mapping. Journal of Environmental Management 197:706-718. https://doi.org/10.1016/ j.jenvman.2016.12.026

Moorthy, I., L. See, M. Batic, and A. Matheus. 2018. The LandSense engagement platform: connecting citizens with earth observation data to promote environmental monitoring. The ESA Earth Observation Week 12-16. [online] URL: http://pure.iiasa. ac.at/15579

Morgan, T. K. K. B. 2008. The value of a Hapū perspective to municipal water management practice: Mauri and potential contribution to sustainability decision making in Aotearoa New Zealand. Dissertation. University of Auckland, New Zealand.

Newman, G., M. Chandler, M. Clyde, B. McGreavy, M. Haklay, H. Ballard, S. Gray, R. Scarpino, R. Hauptfeld, D. Mellon, and J. Gallo. 2017. Leveraging the power of place in citizen science for effective conservation decision making. Biological Conservation 208:55-64.

O'Neill, S. J., and S. Graham. 2016. (En)visioning place-based adaptation to sea-level rise. Geo: Geography and Environment 3 (2):e00028. https://doi.org/10.1002/geo2.28

Paneque-Gálvez, J., N. Vargas-Ramírez, B. M. Napoletano, and A. Cummings. 2017. Grassroots innovation using drones for Indigenous mapping and monitoring. Land 6(4):86. https://doi. org/10.3390/land6040086

Parkins, J. R., C. Hempel, T. M. Beckley, R. C. Stedman, and K. Sherren. 2015. Identifying energy discourses in Canada with $Q$ methodology: moving beyond the environment versus economy debates. Environmental Sociology 1(4):304-314. https://doi. org/10.1080/23251042.2015.1054016

Perry, R. I., R. E. Ommer, M. Barange, S. Jentoft, B. Neis, and U. R. Sumaila. 2011. Marine social-ecological responses to environmental change and the impacts of globalization. Fish and Fisheries 12(4):427-450. https://doi.org/10.1111/j.1467-2979.2010.00402. $\underline{\mathrm{X}}$

Pert, P. L., R. Hill, K. Maclean, A. Dale, P. Rist, J. Schmider, L. Talbot, and L. Tawake. 2015. Mapping cultural ecosystem services with rainforest aboriginal peoples: integrating biocultural diversity, governance and social variation. Ecosystem Services 13:41-56. http://dx.doi.org/10.1016/j.ecoser.2014.10.012

Pike, K., P. Wright, B. Wink, and S. Fletcher. 2015. The assessment of cultural ecosystem services in the marine environment using Q methodology. Journal of Coastal Conservation 19(5):667-675. http://dx.doi.org/10.1007/s11852-014-0350-Z

Plieninger, T., H. Á. av Rana, N. Fagerholm, G. F. Ellingsgaard, E. Magnussen, C. M. Raymond, A. S. Olaffson, and L. N. Verbrugge. 2018. Identifying and assessing the potential for conflict between landscape values and development preferences on the Faroe Islands. Global Environmental Change 52:162-180. https://doi.org/10.1016/j.gloenvcha.2018.07.006

Pretty, J. 2011. Interdisciplinary progress in approaches to address social-ecological and ecocultural systems. Environmental Conservation 38(2):127-139. http://doi.org/10.1017/S0376892910000937 
Quinlan, A. E., M. Berbés-Blázquez, L. J. Haider, and G. D. Peterson. 2016. Measuring and assessing resilience: broadening understanding through multiple disciplinary perspectives. Journal of Applied Ecology 53(3):677-687. https://doi.org/10.1111/1365-$\underline{2664.12550}$

Radjawali, I., O. Pye, and M. Flitner. 2017. Recognition through reconnaissance? Using drones for counter-mapping in Indonesia. Journal of Peasant Studies 44(4):817-833. https://doi. org/10.1080/03066150.2016.1264937

Reddy, P. 2016. Localising the sustainable development goals (SDGs): the role of local government in context. African Journal of Public Affairs 9(2):1-15.

Redman, C. L. 2014. Should sustainability and resilience be combined or remain distinct pursuits? Ecology and Society 19 (2):37. http://dx.doi.org/10.5751/ES-06390-190237

Reed, M. S., E. D. G. Fraser, and A. J. Dougill. 2006. An adaptive learning process for developing and applying sustainability indicators with local communities. Ecological Economics 59:406-418.

Roberts. L. 2015. The University of Canterbury and sustainability: workshop report. Prepared for The University of Canterbury, Christchurch, New Zealand. [online] URL: https://www. canterbury.ac.nz/media/documents/sustain/2015 UC_Sustainability Report with progress indicators.pdf

Robson, J., P. Ortega, and R. Sutton. 2016. A reversal of climatic trends in the North Atlantic since 2005. Nature Geoscience 9:513-517. https://doi.org/10.1038/ngeo2727

Scholz, R. W. 2011. Environmental literacy in science and society: from knowledge to decisions. Cambridge University Press, Cambridge, UK.

Scholz, R. W., and C. Binder. 2003. The paradigm of humanenvironment systems. Working Paper 37. ETH, Zurich, Switzerland. https://doi.org/10.3929/ethz-a-004520890

Shirk, J. L., H. L. Ballard, C. C. Wilderman, T. Phillips, A. Wiggins, R. Jordan, E. McCallie, M. Minarchek, B. V. Lewenstein, M. E. Krasny, and R. Bonney. 2012. Public participation in scientific research: a framework for deliberate design. Ecology and Society 17(2):29. https://doi.org/10.5751/ ES-04705-170229

Smith, K. 2013. Environmental hazards: assessing risk andreducing disaster. Sixth edition. Routledge, New York, New York, USA.

Statistics Canada. 2017. Census Profile, 2016 Census: Drayton Valley, Alberta. Statistics Canada, Ottawa, Ontario, Canada. [online] URL: https://www12.statcan.gc.ca/census-recensement/2016/ dp-pd/prof/details/page.cfm?Lang=E\&Geo1=CSD\&Code1 $=48-$ $11031 \&$ Geo $2=$ PR \&Code $2=48 \&$ SearchText $=$ Drayton $\%$ 20Valley $\&$ SearchType $=$ Begins $\&$ SearchPR $=01 \& B 1=$ All $\&$ GeoLevel $=$ $\underline{\text { PR\&GeoCode }=4811031 \& \text { TABID }=1 \& \text { type }=0}$

Statistics South Africa. 2011. Govan Mbeki, Mpumalanga. 2011 Census. Statistics South Africa, Pretoria, South Africa. [online] URL: http://www.statssa.gov.za/?page id=993\&id=govan-mbekimunicipality
Statistics South Africa. 2016. Community survey 2016: statistical release. Stats SA Library Cataloguing-in-Publication (CIP) Data. Statistics South Africa, Pretoria, South Africa. [online] URL: http://cs2016.statssa.gov.za/wp-content/uploads/2016/07/NT-30-06-2016RELEASE-for-CS-2016- Statistical-releas 1-July-2016.pdf

Steinberg, S. J., and S. J. Steinberg. 2015. GIS research methods: incorporating spatial perspectives. Esri Press, Redlands, California, USA.

Sterling, E., A. Sigouin, E. Betley, P. Pascua, C. Rivera, A. Toomey, and N. Gazit. 2018. Developing effective wellbeing indicators for people and nature: how biocultural approaches can facilitate sustainable management of social-ecological systems. 5th European Congress of Conservation Biology. Jyväskylä, Finland. https://doi.org/10.17011/conference/eccb2018/107589

Tabor, K., and J. Hewson. 2018. The evolution of remote sensing applications vital to effective biodiversity conservation and sustainable development. Pages 274-300 in A. K. Leidner and G. M. Buchanan, editors. Satellite remote sensing for conservation action: case studies from aquatic and terrestrial ecosystems. Cambridge University Press, Cambridge, UK. https://doi. org/10.1017/9781108631129.010

Teitelbaum, S., A. Montpetit, J. F. Bissonnette, C. Chion, G. Chiasson, F. Doyon, J. Dupras, M.-J. Fortin, É. Leclerc, C. StAmour, and J. Tardif. 2019. Studying resource-dependent communities through a social-ecological lens? Examining complementarity with existing research traditions in Canada. Society \& Natural Resources 32(1):93-112. https://doi. org/10.1080/08941920.2018.1517913

Tschakert, P., N. Tuana, H. Westskog, B. Koelle, and A. Afrika. 2016. T ${ }^{\text {CHANGE}}$ : the role of values and visioning in transformation science. Current Opinion in Environmental Sustainability 20:21-25. https://doi.org/10.1016/j.cosust.2016.04.003

Ungar, M. 2018. Systemic resilience: principles and processes for a science of change in contexts of adversity. Ecology and Society 23(4):34. https://doi.org/10.5751/ES-10385-230434

United Nations. 2019. Sustainable development goals knowledge platform. UN, New York, New York, USA. [online] URL: https:// sustainabledevelopment.un.org/?menu $=1300$

Vaidya, A. 2016. The utility of the participatory approach for sustainable development assessments. Dissertation. Michigan Technological University, Houghton, Michigan, USA. [online] URL: https://digitalcommons.mtu.edu/etdr/215

Vaidya, A., and A. L. Mayer. 2014. Use of the participatory approach to develop sustainability assessments for natural resource management. International Journal of Sustainable Development \& World Ecology 21(4):369-379. https://doi. org/10.1080/13504509.2013.868376

Wali, A., D. Alvira, P. S. Tallman, A. Ravikumar, and M. O. Macedo. 2017. A new approach to conservation: using community empowerment for sustainable well-being. Ecology and Society 22(4):6. https://doi.org/10.5751/ES-09598-220406

Walker, B., C. S. Holling, S. R. Carpenter, and A. Kinzig. 2004. Resilience, adaptability and transformability in social-ecological 
systems. Ecology and Society 9(2):5. https://doi.org/10.5751/ ES-00650-090205

Walker, B., and D. Salt. 2006. Resilience thinking: sustaining ecosystems and people in a changing world. Island, Washington, D.C., USA.

Weldegiorgis, F. S., and S. H. Ali. 2016. Mineral resources and localised development: Q-methodology for rapid assessment of socioeconomic impacts in Rwanda. Resources Policy 49:1-11. https://doi.org/10.1016/j.resourpol.2016.03.006

Whatmore, S. 2002. Hybrid geographies: natures cultures spaces. SAGE, London, UK. 